\title{
MicroRNA-124 expression in the brains of rats during early cerebral ischemia and reperfusion injury is associated with cell apoptosis involving STAT3
}

\author{
WENTING ZHANG and AIGUO MENG
}

\author{
Department of Laboratory Medicine, Affiliated Hospital and School of Clinical Medicine, \\ North China University of Science and Technology, Tangshan, Hebei 06300, P.R. China
}

Received April 16, 2017; Accepted January 10, 2019

DOI: $10.3892 /$ etm.2019.7220

\begin{abstract}
Cerebral ischemia and reperfusion injury is a cause of death and disability in adults. MicroRNA-124 possesses protective effects against apoptosis in cerebral ischemia and reperfusion. To provide insights into the diagnosis and treatment of cerebral ischemia and reperfusion injury, the dynamic changes of microRNA-124 expression during the early stage of cerebral ischemia and reperfusion injury in rats was investigated by quantitative polymerase chain reaction. To elucidate the association between the dynamic expression of microRNA-124 and apoptosis, the expression of proteins associated with apoptosis, including caspase-3, apoptosis regulator $\mathrm{Bcl}-2(\mathrm{Bcl}-2)$ and apoptosis regulator $\mathrm{Bax}(\mathrm{Bax})$ was analyzed by immunohistochemistry and western blot analyses. As signal transducer and activator of transcription 3 (STAT3) is involved in cell apoptosis and associated with Bcl-2, the protein expression of STAT3 and its active form, phosphorylated (p-)STAT3, were analyzed by western blot analysis. The expression of microRNA-124 increased and the maximum value appeared $12 \mathrm{~h}$ after reperfusion. Similarly, the expression of Bcl-2 also peaked $12 \mathrm{~h}$ after reperfusion, however the expression of caspase- 3 and Bax continued to increase after the $12 \mathrm{~h}$ time point. These results indicate that the expression of microRNA-124 is closely associated with Bcl-2 and serves a protective role, inhibiting apoptosis. As the upstream regulator of Bcl-2, the expression of p-STAT3 was in accordance with Bcl-2 expression and peaked $12 \mathrm{~h}$ after reperfusion. By contrast, STAT3 was downregulated and the minimum level of STAT3 protein was reached $12 \mathrm{~h}$ after reperfusion. In summary,
\end{abstract}

Correspondence to: Dr Aiguo Meng, Department of Laboratory Medicine, Affiliated Hospital and School of Clinical Medicine, North China University of Science and Technology, 73 South Jianshe Road, Tangshan, Hebei 06300, P.R. China

E-mail: tangshan20150101@sina.cn

Key words: cerebral ischemia/reperfusion, microRNA-124, apoptosis, signal transducer and activator of transcription 3, dynamic changes during the early stage of cerebral ischemia and reperfusion, the dynamic expression of microRNA-124 exhibited protective effects through the inhibition of apoptosis via anti-apoptotic proteins Bcl-2 and STAT3. Conversely, caspase-3 and Bax maintain apoptosis. The present study provides evidence to aid in the understanding of cerebral ischemia and reperfusion injury and develops methods of diagnosis and therapy of this condition.

\section{Introduction}

Cerebral ischemia, which results from the occlusion of an artery in brain, is a leading cause of morbidity and mortality in adults all over the world (1). During ischemia and the subsequent condition, reperfusion, the decline of cerebral blood flow leads to the deprivation of oxygen and glucose, and determines the severity of the ischemic insult (2). An ischemic insult is an area where there is a complete absence of blood flow and neuronal death occurs. Around the insult is an ischemic penumbra, in this area blood flow is reduced and function is impaired, however metabolism remains active (3). If blood flow is not restored in a short time, the neurons in the penumbra enter apoptosis (4). Traditionally, necrosis is considered the major cell death pathway in cerebral ischemia, but studies in the past decades have revealed that in the first few hours after ischemia neurons in the ischemic penumbra transiently undergo reversible damage and ultimately apoptosis $(2,5)$. Although the duration of ischemia is a crucial factor of brain tissue damage, subsequent reperfusion also serves a prominent role in the acceleration of irreversible damage (6). Therefore, the initial few hours of reversible neuronal injury provides an opportunity for therapeutic intervention (2).

MicroRNAs are small non-coding RNAs 18-25 nucleotides in length, which can bind to the 3'-untranslated region of mRNAs to achieve downregulation of the target mRNA via degradation or translational inhibition (7). Previous studies have demonstrated that microRNAs served a role in the therapy of cerebral ischemia and reperfusion injury (8-10). In response to cerebral ischemia, microRNA expression was dynamic; among these microRNAs, microRNA-124 was expressed at high levels in the central nervous system (7). MicroRNA-124 protected neurons against cerebral ischemia 
through multiple molecular mechanisms (11-13) and showed promising therapeutic potential for the treatment of central nervous system diseases (14). In addition, microRNA-124 possessed anti-cancer effects (15-17) and was hepatoprotective (18). To better understand cerebral ischemia and reperfusion injury, and how to provide effective therapeutic intervention, the present study examined the changes in microRNA-124 expression in the brain tissue of rats during early ischemia and reperfusion. The tissue was examined at different time points and the association with cell apoptosis involving STAT3 activation was investigated.

\section{Materials and methods}

Chemicals and reagents. Water was prepared from water distilled by Millipore Milli-Q ${ }^{\circledR}$ system (EMD Millipore, Billerica, MA, USA). Antibodies directed against apoptosis regulator Bcl-2 (Bcl-2; cat. no. 610538) were purchased from BD Biosciences (Franklin Lakes, NJ, USA). Anti-apoptosis regulator Bax (Bax; cat. no. AF0120), -caspase-3 (cat. no. AF7022) and - $\beta$-tubulin (cat. no. T0023) antibodies were obtained from Affinity Biosciences (Cincinnati, $\mathrm{OH}$, USA). The total RNA extraction kit and microRNA-124 reverse transcription-quantitative polymerase chain reaction (RT-qPCR) kit were supplied by Suzhou Jima Gene Co. Ltd. (Suzhou, China). Anti-signal transducer and activator of transcription 3 (STAT3; cat. no. ARH4012) and -phosphorylated (p-)STAT3 (cat. no. ARE6058) antibodies were purchased from AR Biosciences USA, Inc. (San Diego, CA, USA).

Animals. A total of 54 male Sprague Dawley rats (250-280 g, $8.0 \pm 0.5$ weeks) were supplied by the Experimental Animals Center of North China University of Science and Technology (Tangshan, China). The animals were housed in controlled conditions (temperature, $23 \pm 2^{\circ} \mathrm{C}$; humidity, $45-60 \% ; 12 \mathrm{~h}$ light/dark cycle; free access to water and a standard diet). All animal experiments were performed in accordance with the Guide for the Care and Use of Laboratory Animals guidelines (National Institutes of Health, Bethesda, MD, USA) (19), with the approval of the Animal Care and Use Committee of North China University of Science and Technology.

Middle cerebral artery occlusion $(M C A O)$. The rats were subjected to MCAO, as previous description (20). Briefly, the rats were anesthetized with $10 \%$ chloral hydrate $[350 \mathrm{mg} / \mathrm{kg}$, intraperitoneal injection (IP)]. The internal, external and right common carotid arteries were exposed surgically. A 3600AAA monofilament nylon suture (Guangzhou Jialing Biotech Co., Ltd., Guangzhou, China) was inserted into the internal carotid artery through the external carotid artery stump and the MCA was occluded. To ensure MCAO caused ischemia, the rats above grade 2 in neurologic examination were considered successful models, as previously described (21). After $2 \mathrm{~h}$ of MCAO, the suture was removed to restore blood flow. At certain time points $(3,6,12$ and $24 \mathrm{~h}$ after reperfusion), the rats were sacrificed under anesthesia [10\% chloral hydrate (350 mg/kg, IP)] by decapitation to get the brain tissue on ice as previously described (22). The brain tissue was stored under $-80^{\circ} \mathrm{C}$ until they were analyzed. The rats in the sham group underwent the same surgery after $3 \mathrm{~h}$, but the MCA was not occluded.

RNA extraction and RT-qPCR analysis. The total RNA was extracted from the brain tissue by a single-step method using TRIzol ${ }^{\circledR}$ reagent (Invitrogen; Thermo Fisher Scientific, Inc., Waltham, MA, USA) according to manufacturer's protocol. The concentration and integrity of RNA were determined by Hairpin-it ${ }^{\mathrm{TM}}$ miRNA qPCR Quantitation kit (cat. no. QPM-012; Suzhou GenePharma Co., Ltd., Suzhou, China) according to the manufacturer's protocol. An RT-qPCR analysis was performed on the $\mathrm{iQ}^{\mathrm{TM}} 5$ Real-Time PCR system (Bio-Rad Laboratories, Inc., Hercules, CA, USA) under following conditions: $95^{\circ} \mathrm{C}$ for $3 \mathrm{~min}$, and 40 cycles of $95^{\circ} \mathrm{C}$ for $12 \mathrm{sec}$ and $62^{\circ} \mathrm{C}$ for $40 \mathrm{sec}$. Primers for microRNA-124 and U6 were supplied in the Hairpin-it ${ }^{\mathrm{TM}}$ miRNA qPCR Quantitation kit. The microRNA-124 and U6, the internal control, were detected using a U6 real time RT-qPCR normalization kit (Suzhou GenePharma Co., Ltd.) according to the manufacturer's protocol. The relative quantification value for the target gene was calculated using the $2^{-\Delta \Delta \mathrm{Cq}}$ method (23).

Immunohistochemical analysis. At the aforementioned time points, the rats were sacrificed by decapitation under deep anesthesia with $10 \%$ chloral hydrate $(350 \mathrm{mg} / \mathrm{kg}$, IP), then perfused with $10 \%$ paraformaldehyde at room temperature for $10 \mathrm{~min}$ and washed with saline. The whole brain was removed and immersed in $10 \%$ paraformaldehyde for $24 \mathrm{~h}$ at $4^{\circ} \mathrm{C}$. The tissues were rinsed with $\mathrm{PBS}$, dehydrated through gradients of alcohol and xylene, and then embedded in paraffin. Brain sections (5- $\mu$ m-thick) were prepared on the RM2245 Semi-Automated Rotary Microtome (Leica Microsystems $\mathrm{GmbH}$, Wetzlar, Germany). The sections was rehydrated in descending alcohol series at room temperature. The antigen retrieval was implemented in $0.01 \mathrm{M}$ citrate buffer solution in an autoclave at $95^{\circ} \mathrm{C}$ for $1 \mathrm{~min}$. The sections were cooled to room temperature and washed with PBS three times. Then the sections were incubated in $3 \% \mathrm{H}_{2} \mathrm{O}_{2}$ for 15 min to block endogenous peroxidase and subsequently washed with 0.01 M PBS three times for $3 \mathrm{~min}$ each time. Then the sections were blocked in buffer with $10 \%$ goat serum from a SPlink detection kit (cat. no. AR100089; OriGene Technologies, Inc., Beijing, China) at room temperature for $15 \mathrm{~min}$. Caspase-3, Bcl-2 and Bax primary antibodies (1:500 dilution) were added to the sections and incubated overnight at $4^{\circ} \mathrm{C}$. The sections were washed with $0.01 \mathrm{M}$ PBS for 3 min again. Then the goat anti-rat immunoglobulin (Ig)G secondary antibodies conjugated to biotin from the SPlink detection kit were applied and incubated at room temperature for $15 \mathrm{~min}$ followed by the addition of an avidin-biotin-horseradish peroxidase complex solution from the SPlink detection kit at room temperature for another $15 \mathrm{~min}$. The sections were treated with 3,3'-Diaminobenzidine tetrahydrochloride as the color substrate at room temperature for $5 \mathrm{~min}$. Then the sections were rinsed with water and stained by hematoxylin at room temperature for $5 \mathrm{~min}$. The labeled sections were examined under an inverted optical microscope at a magnification of $x 400$. With the exception of the incubation of the primary antibodies, the procedure was the same for the control groups. 
Western blot analysis. Western blot analyses were employed to determine the expression of cleaved caspase-3, Bcl-2, Bax, STAT3 and p-STAT3. In short, total protein was extracted using Whole Cell Lysis Assay kit (cat. no. KGP2100; Nanjing KeyGen Biotech Co., Ltd., Nanjing, China) from brain tissue and quantified by a bicinchoninic acid assay kit according to the manufacturer's protocol. Then the samples (30 $\mu \mathrm{g} /$ lane) were denatured at $95^{\circ} \mathrm{C}$ for $30 \mathrm{~min}$ and separated by SDS-PAGE on a $15 \%$ gel. The samples were then transferred to polyvinylidene difluoride membranes. Following blocking of the membranes with $5 \%$ skimmed milk at $37^{\circ} \mathrm{C}$ for $1 \mathrm{~h}$, the membranes were incubated overnight with anti-caspase-3, -Bcl-2, -Bax, -STAT3, -p-STAT3 and - $\beta$-tubulin primary antibodies $\left(1: 1,000\right.$ dilution) at $4^{\circ} \mathrm{C}$. The goat anti-rat IgG secondary antibodies conjugated to horseradish peroxidase (1:1,000 dilution; cat no. A0192; Beyotime Institute of Biotechnology, Shanghai, China) were added and incubated at room temperature for $2 \mathrm{~h}$. The results were detected by enhance chemiluminescence substrate (cat no. P0018; Beyotime Institute of Biotechnology) on Azure c300 Chemiluminescent Western Blot Imaging System (Azure Biosystems, Inc., Dublin, CA, USA). $\beta$-tubulin (1:1,000 dilution) was used as the internal control. Densitometric analysis was performed by Image J software (version 1.5; National Institutes of Health) to obtain the relative intensities of the bands.

Statistical analysis. All results are expressed as mean \pm standard deviation. GraphPad Prism software (version 5.0; GraphPad Software, Inc., La Jolla, CA, USA) analyzed the results. Statistical differences were compared by one-way analysis of variance followed by Dunnett's test for comparisons between multiple groups and Student's t-test for comparisons between two groups. $\mathrm{P}<0.05$ was considered to indicate a statistically significant difference.

\section{Results}

MicroRNA-124 expression increases in ischemic brain tissue in the 12 hafter reperfusion. The expression of microRNA-124 in the sham group was similar to that of the control group (Fig. 1). However, $3 \mathrm{~h}$ after reperfusion, compared with the sham group, the expression of microRNA-124 in the brain tissue of experimental rats was significantly elevated at $2.74 \pm 0.32$. Then at the $6 \mathrm{~h}$ time point, the expression reached $4.70 \pm 0.62$, which was significant increased compared with the $3 \mathrm{~h}$ treatment group. MicroRNA-124 expression at the $12 \mathrm{~h}$ time point was $\sim 6$ times that of the control group at $6.77 \pm 0.67$, which was a significant increase compared with the $6 \mathrm{~h}$ treatment group. At $24 \mathrm{~h}$, the expression of microRNA-124 was 5.30 0.76 , which was similar to the $6 \mathrm{~h}$ and significantly reduced compared with the $12 \mathrm{~h}$ treatment group. These results demonstrate that microRNA-124 expression is dynamic following reperfusion and neuronal injury.

Caspase-3 expression increases in ischemic brain tissue in the $24 \mathrm{~h}$ after MCAO and reperfusion. As a member of the cysteine-dependent aspartate-directed protease family, caspase-3 is an effector enzyme involved in cell apoptosis (24). An immunohistochemical analysis revealed that the expression of caspase- 3 was upregulated following MCAO

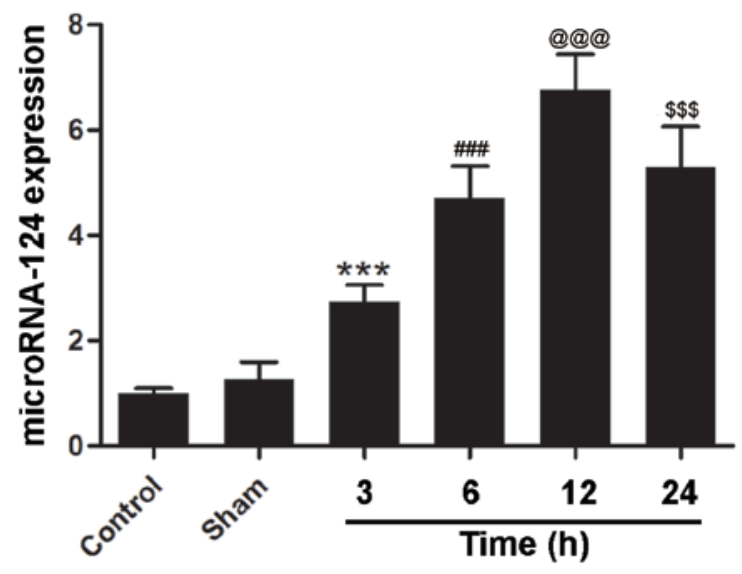

Figure 1. MicroRNA-124 expression increases following cerebral ischemia and reperfusion in the brain tissue of rats, peaking after $12 \mathrm{~h} . \mathrm{n}=6{ }^{* * *} \mathrm{P}<0.001$ vs. the sham group, ${ }^{\# \#} \mathrm{P}<0.001$ vs. the $3 \mathrm{~h}$ treatment group, ${ }^{@ @ @ ~} \mathrm{P}<0.001$ vs. the $6 \mathrm{~h}$ treatment group and ${ }^{\$ \$} \mathrm{P}<0.001$ vs. the $12 \mathrm{~h}$ treatment group.

and reperfusion, although the expression of caspase- 3 was not evident in the control group (Fig. 2). Western blotting confirmed the aforementioned results and gave a profile of caspase-3 expression in relative levels (Fig. 3). Following a densitometric analysis, caspase- 3 expression was identified to be significantly upregulated $3 \mathrm{~h}$ after MCAO and reperfusion $(0.49 \pm 0.01)$ compared with the sham group; the expression level of caspase- 3 continued to increase significantly $24 \mathrm{~h}$ after reperfusion $(0.91 \pm 0.01$; Fig. 4) compared with the $12 \mathrm{~h}$ treatment group. These results demonstrate that neuronal apoptosis follows MCAO and reperfusion, and that the injury worsens with time at the early stage of cerebral ischemia and reperfusion.

Bcl-2 and Bax exhibit similar expression levels in ischemic brain tissue as their expression increases following MCAO and reperfusion. An immunohistochemical analysis revealed the dynamic expression of Bcl-2 and Bax following MCAO and reperfusion. The expression of Bax increased similarly to caspase-3 following MCAO and reperfusion (Fig. 5). By contrast, Bcl-2 expression increased and peaked $12 \mathrm{~h}$ after MCAO and reperfusion (Fig. 6), which was in accordance with the dynamic changes of microRNA-124. Western blotting confirmed these results (Fig. 3) and the densitometric analysis of the relative levels of $\mathrm{Bcl}-2$ and $\mathrm{Bax}$ supported the results quantitatively (Fig. 7A). Bcl-2 and Bax were significantly upregulated at the 3,6,12 and $24 \mathrm{~h}$ time points compared with the sham group and, 3, 6 and $12 \mathrm{~h}$ treatment groups, respectively. Additionally, the relative ratio of Bcl-2 and Bax demonstrated that the protein expression increased following MCAO and reperfusion, peaked at $12 \mathrm{~h}$, and then decreased (Fig. 7B).

STAT3 and p-STAT3 exhibit opposing expression profiles, with $p$-STAT3 expression increasing following MCAO and reperfusion in ischemic brain tissue. To investigate the involvement of STAT3 in cerebral ischemia and reperfusion, STAT3 and p-STAT3 were analyzed by western blotting and western blot analysis. No significant differences in the expression of STAT3 and p-STAT3 were identified between the control 

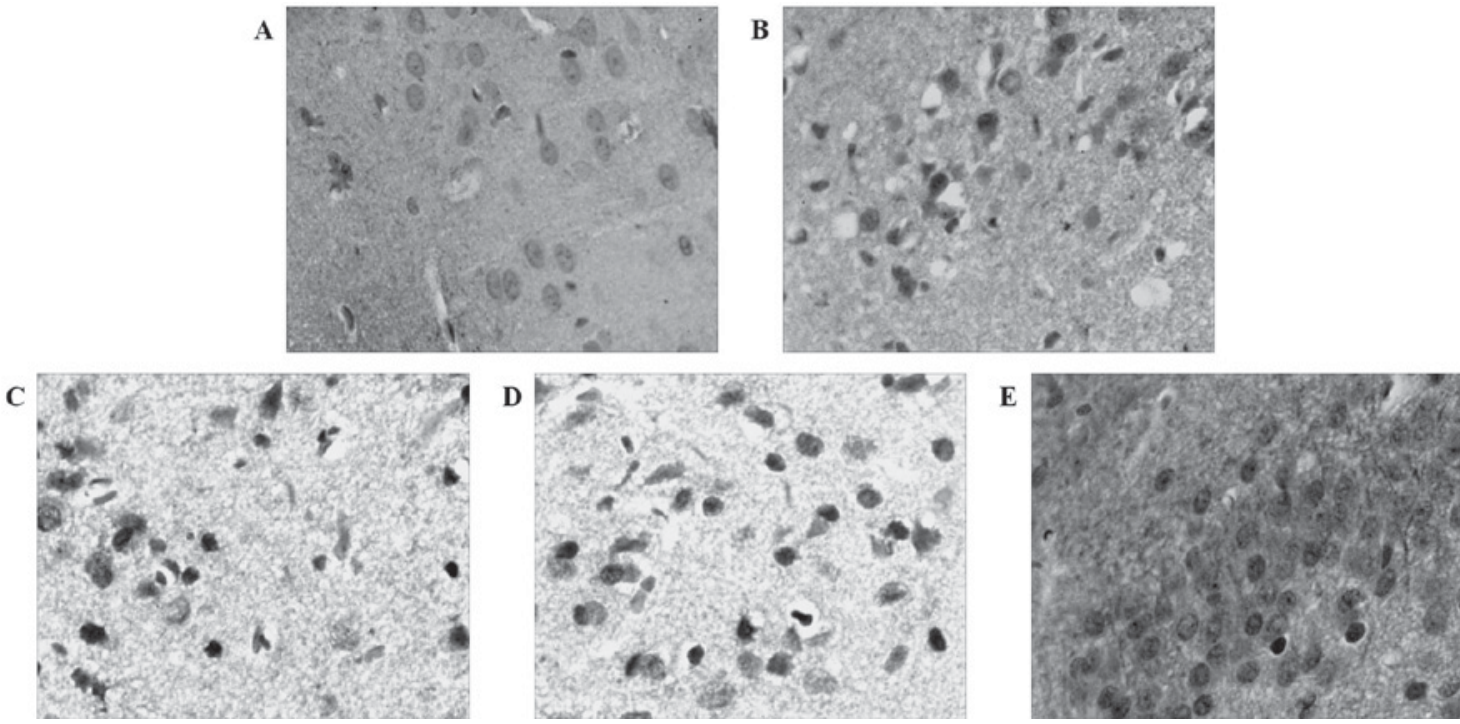

Figure 2. Caspase-3 is upregulated following cerebral ischemia and reperfusion in the brain tissue of rats. Immunohistochemical analysis of caspase-3 expression in (A) the control group, and (B) 3, (C) 6, (D) 12 and (E) $24 \mathrm{~h}$ after cerebral ischemia and reperfusion.

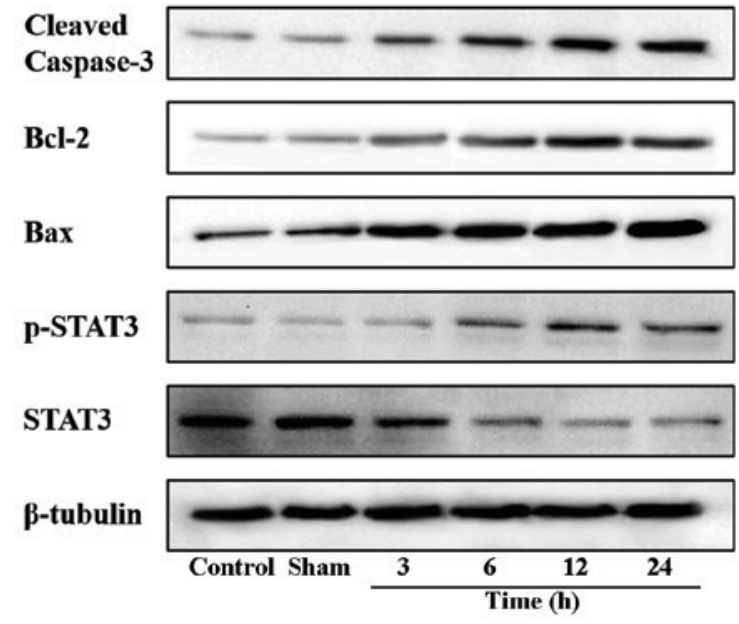

Figure 3. Protein expression of proteins associated with apoptosis in the brain tissue of rats. Western blotting of the changes in the protein expression levels. $\mathrm{Bcl}-2$, apoptosis regulator Bcl-2; Bax, apoptosis regulator Bax; STAT3, signal transducer and activator of transcription 3; p-, phosphorylated.

group and the sham group, although p-STAT3 expression was low (Figs. 3 and 8). Following MCAO and reperfusion, STAT3 was activated through phosphorylation, which led to a significant upregulation of p-STAT3 at $3 \mathrm{~h}$ compared with the sham group. Following MCAO and reperfusion, p-STAT3 expression peaked at $12 \mathrm{~h}$, which was significantly greater compared with the expression at $6 \mathrm{~h}$, then significantly declined at the $24 \mathrm{~h}$ time point. Accordingly, compared with the sham group, STAT3 was significantly reduced after $3 \mathrm{~h}$ of MCAO and reperfusion, and after $12 \mathrm{~h}$ STAT3 expression reached its minimum level, which was significantly reduced compared with the expression at $6 \mathrm{~h}$. At the $24 \mathrm{~h}$ time point, STAT3 expression was significantly upregulated compared with the $12 \mathrm{~h}$ treatment group. These results were consistent with the dynamic expression of Bcl-2 and microRNA-124, thus an association between STAT3, Bcl-2 and microRNA-124 was indicated.

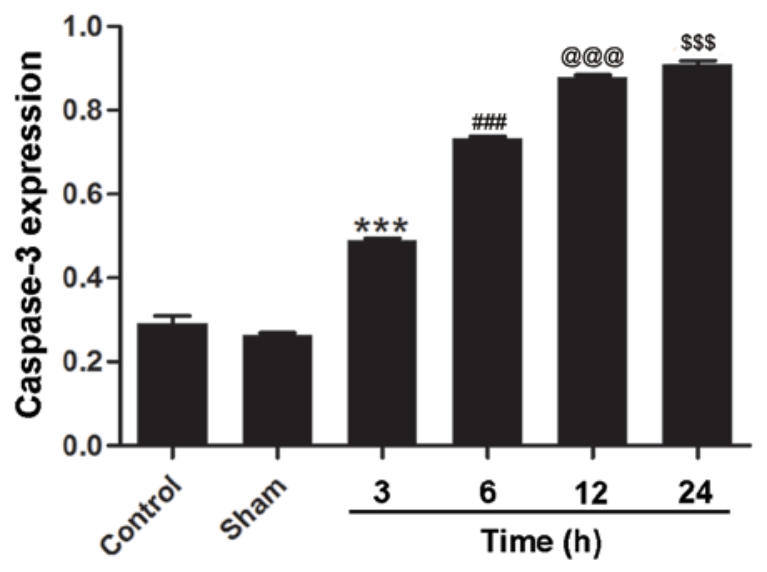

Figure 4. Caspase-3 protein expression is upregulated following cerebral ischemia and reperfusion in the brain tissue of rats. Densitometric analysis of western blotting of caspase-3 protein expression levels. $n=3$. $^{* * *} \mathrm{P}<0.001$ vs. the sham group, ${ }^{\# \#} \mathrm{P}<0.001$ vs. the $3 \mathrm{~h}$ treatment group, ${ }^{@ @ @ ~} \mathrm{P}<0.001$ vs. the $6 \mathrm{~h}$ treatment group and ${ }^{\$ \$} \mathrm{P}<0.001 \mathrm{vs}$. the $12 \mathrm{~h}$ treatment group.

\section{Discussion}

Cerebral ischemia and reperfusion injury results from a deficiency in cerebral blood flow, as well as subsequent oxygen and glucose deprivation, and restoration (2). Apoptosis contributes largely to cell death in cerebral ischemia and reperfusion injury (2). As a microRNA specifically expressed in brain tissue, microRNA-124 can protect cells from apoptosis in cerebral ischemic areas (11). The results of the present study demonstrated that the expression of microRNA-124 in brain tissue was dynamic during the early stage of cerebral ischemia and reperfusion injury, and the level of microRNA-124 expression peaked at the $12 \mathrm{~h}$ time point. This result supports the hypothesis that microRNA-124 attenuates the injury induced by cerebral ischemia and reperfusion during the early stage.

Caspase-3 is a member of the cysteine-dependent aspartate-directed protease family and was revealed to drive the 

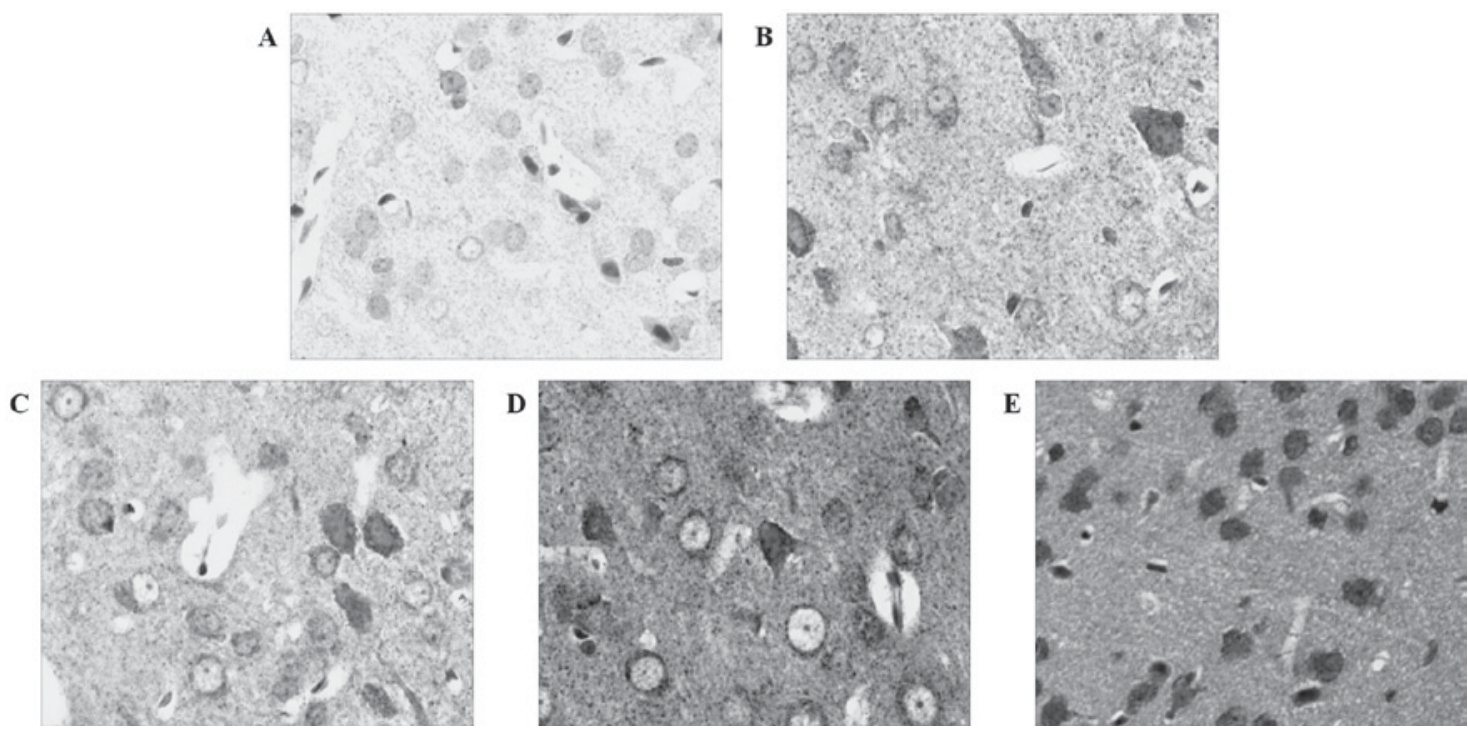

Figure 5. Bax is upregulated following cerebral ischemia and reperfusion in the brain tissue of rats. Immunohistochemical analysis of Bax expression in (A) the control group, and (B) 3, (C) 6, (D) 12 and (E) $24 \mathrm{~h}$ after cerebral ischemia and reperfusion. Bax, apoptosis regulator Bax.
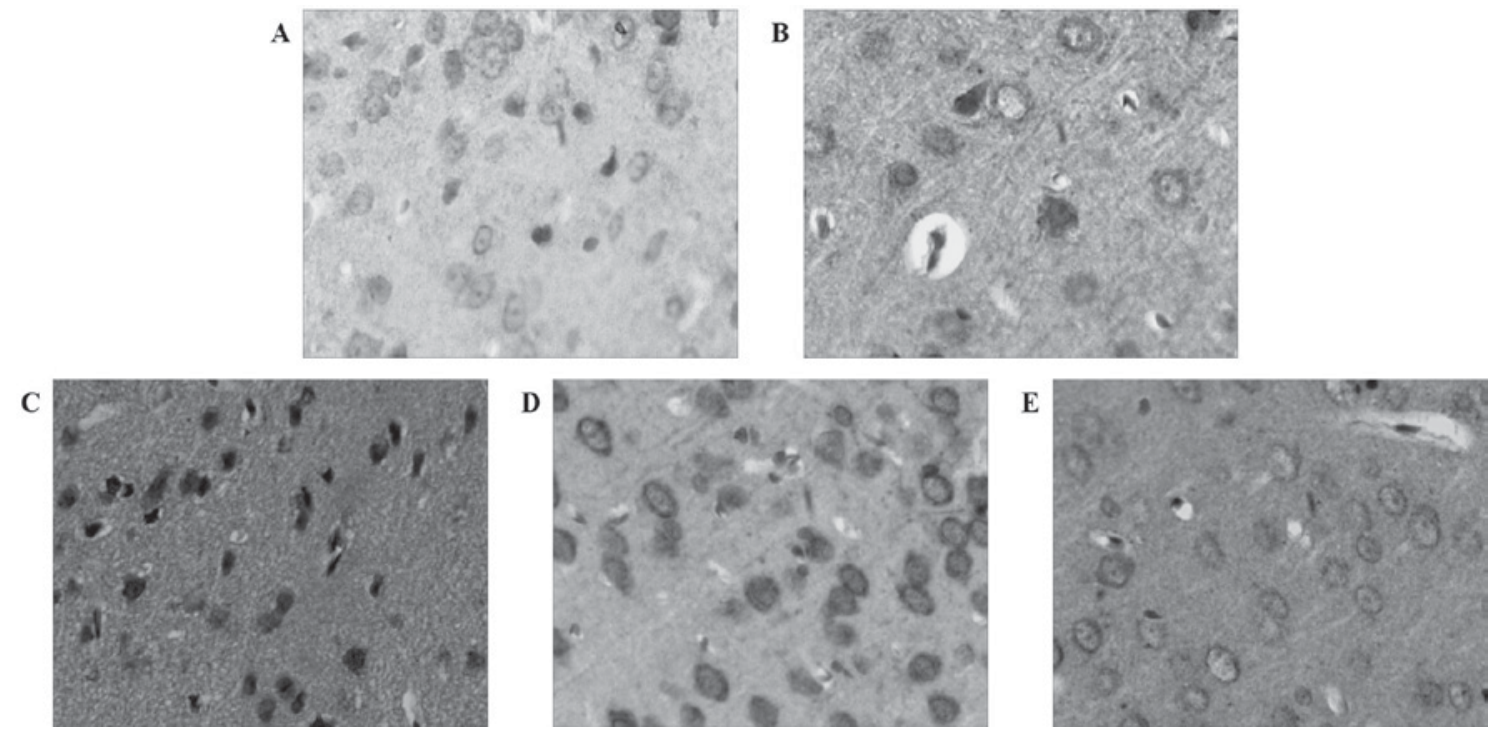

Figure 6. Bcl-2 is upregulated following cerebral ischemia and reperfusion in the brain tissue of rats. Immunohistochemical analysis of Bcl-2 expression in (A) the control group, and (B) 3, (C) 6, (D) 12 and (E) $24 \mathrm{~h}$ after cerebral ischemia and reperfusion. Bcl-2, apoptosis regulator Bcl-2.

mitochondria- and death receptor-mediated signaling pathways in apoptosis (25). Caspase-3 is activated through the cleavage of pro-caspase-3, the cleaved caspase-3 served a role in mitochondria-mediated apoptosis (3). Bcl-2 and Bax are members of the Bcl-2 protein family, which regulates various cellular activities (26). Bcl-2 and Bax were also involved in cerebral ischemia through the modulation of mitochondria-mediated apoptosis (2). Bcl-2 exhibits an anti-apoptotic effect and inhibits the activation of caspase- 3 while Bax demonstrates a pro-apoptotic effect (27). In addition, Bax can dimerize, dimerized Bax initiates the activation of terminal caspases, which results in the promotion of apoptosis (27). Conversely, the heterodimer of $\mathrm{Bcl}-2 / \mathrm{Bax}$ prevents certain downstream events in apoptosis (26). In the present study, the expression of caspase- 3 and Bax increased during the early stage of cerebral ischemia and reperfusion, which indicated that the injury was being exacerbated. On the contrary, the expression of Bcl-2 increased prior to the injury and reached peak expression at the $12 \mathrm{~h}$ time point, following by a decrease. Accordingly, the ratio of Bcl-2/Bax was highest $12 \mathrm{~h}$ after MCAO and reperfusion. These results were consistent with the dynamic expression of microRNA-124, which implies that Bcl-2 is involved in the protection of the brain against cerebral ischemia and reperfusion injury, and that caspase- 3 and Bax are promoters of that injury.

STAT3 serves an important role in the regulation of cell apoptosis. STAT3, an inactive protein, can be activated through phosphorylation upon neural injury to exert a protective effect (28). p-STAT3 is involved in the tyrosine-protein kinase JAK (JAK)2/STAT3 signaling pathway to promote cell viability (29) and protect the brain against cerebral ischemia injury (30). As the substrate of STAT3, Bcl-2 was 

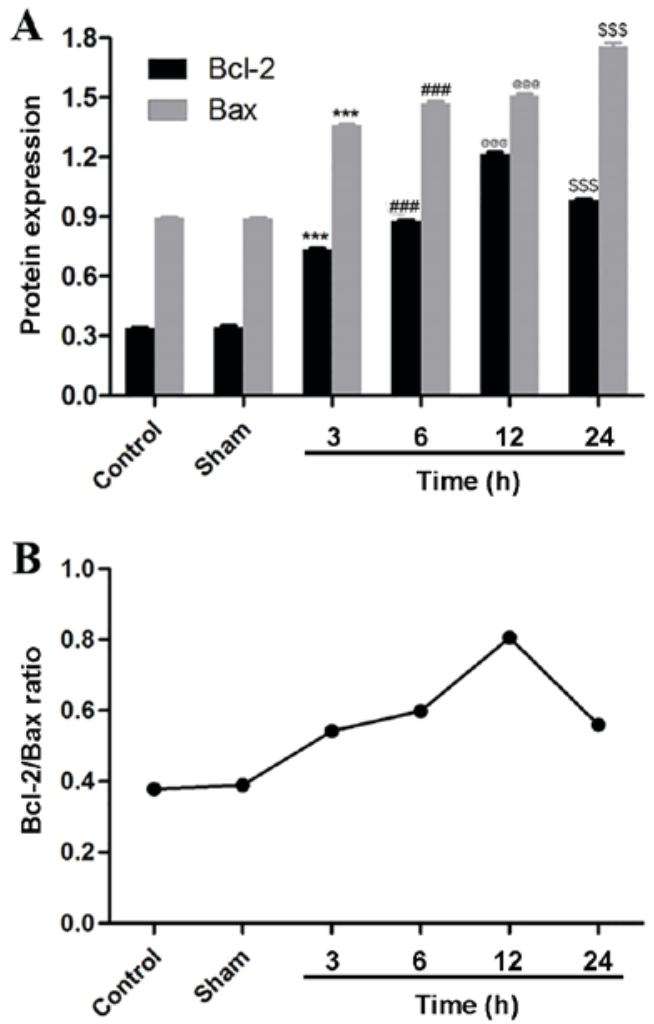

Figure 7. Bcl-2 and Bax exhibit similar expression profiles following cerebral ischemia and reperfusion in the brain tissue of rats. (A) The protein expression of $\mathrm{Bcl}-2$ and $\mathrm{Bax} . \mathrm{n}=3{ }^{*{ }^{* * *} \mathrm{P}}<0.001$ vs. the sham group, ${ }^{\# \# \#} \mathrm{P}<0.001$ vs. the $3 \mathrm{~h}$ treatment group, ${ }^{\circledR @ @ ~}{ }^{\circledR} \mathrm{P}<0.001$ vs. the $6 \mathrm{~h}$ treatment group and ${ }^{\$ \$ \$} \mathrm{P}<0.001$ vs. the $12 \mathrm{~h}$ treatment group. (B) The ratio of $\mathrm{Bcl}-2 / \mathrm{Bax}$ protein expression. $\mathrm{Bcl}-2$, apoptosis regulator $\mathrm{Bcl}-2$; $\mathrm{Bax}$, apoptosis regulator Bax.

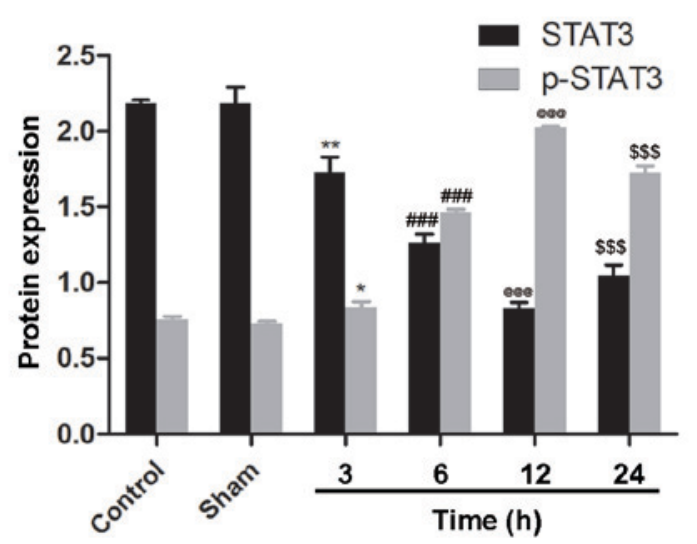

Figure 8. STAT3 and p-STAT3 exhibit opposite expression profiles following cerebral ischemia and reperfusion in the brain tissue of rats. $n=3$. ${ }^{*} \mathrm{P}<0.05$ and ${ }^{* *} \mathrm{P}<0.01$ vs. the sham group, ${ }^{\# \# \#} \mathrm{P}<0.001$ vs. the $3 \mathrm{~h}$ treatment group, ${ }^{\circledR @ @ ~} \mathrm{P}<0.001$ vs. the $6 \mathrm{~h}$ treatment group and ${ }^{\$ \$ \$} \mathrm{P}<0.001$ vs. the $12 \mathrm{~h}$ treatment group. STAT3, signal transducer and activator of transcription 3; p-, phosphorylated.

regulated by p-STAT3 during cerebral ischemia (31). The present study determined that the expression of p-STAT3 was upregulated and peaked $12 \mathrm{~h}$ after MCAO and reperfusion, and then the expression decreased. Accordingly, the expression of STAT3 was downregulated and its lowest level was at the $12 \mathrm{~h}$ time point. This trend mirrored microRNA-124 and Bcl-2 expression, which suggests that STAT3 is associated with Bcl-2.

In conclusion, the present study elucidated the dynamic expression of microRNA-124 during the early stage of cerebral ischemia and reperfusion. Anti-apoptotic proteins, including Bcl-2, STAT3 and p-STAT3 exhibit similar changes in their expression, synchronous with microRNA-124, protecting brain tissue from injury. Pro-apoptotic proteins, including caspase-3 and Bax, were consistently upregulated following reperfusion. This present study reveals that the protective effect of microRNA-124 is associated with Bcl-2 and involved in the JAK2/STAT3 signaling pathway. This gives insight into the possible diagnosis of and therapy for cerebral ischemia and reperfusion injury.

\section{Acknowledgements}

Not applicable.

\section{Funding}

No funding was received.

\section{Availability of data and materials}

The datasets used and/or analyzed during the current study are available from the corresponding author on reasonable request.

\section{Authors' contributions}

WZ designed the study, performed the collection, analysis and interpretation of data, and wrote the manuscript. AM designed the study, performed the analysis and interpretation of data, and revised this manuscript.

\section{Ethics approval and consent to participate}

The current study was approved by the Animal Care and Use Committee of North China University of Science and Technology (Tangshan, China).

\section{Patient consent for publication}

Not applicable.

\section{Competing interests}

The authors declare that they have no competing interests.

\section{References}

1. Flynn RW, MacWalter RS and Doney AS: The cost of cerebral ischemia. Neuropharmacology 55: 250-256, 2008.

2. Mehta SL, Manhas N and Raghubir R: Molecular targets in cerebral ischemia for developing novel therapeutics. Brain Res Rev 54: 34-66, 2007.

3. Ji HJ, Wang DM, Hu JF, Sun MN, Li G, Li ZP, Wu DH, Liu G and Chen NH: IMM-H004, a novel courmarin derivative, protects against oxygen- and glucose-deprivation/restoration-induced apoptosis in PC12cells. Eur J Pharmacol 723: 259-266, 2014. 
4. Endres M, Engelhardt B, Koistinaho J, Lindvall O, Meairs S, Mohr JP, Planas A, Rothwell N, Schwaninger M, Schwab ME, et al: Improving outcome after stroke: Overcoming the translational roadblock. Cerebrovasc Dis 25: 268-278, 2008.

5. Liu DM, Wang ZH, Liu L, Zhang XM and Lou FL: Acetylpuerarin increases cell viability and reduces apoptosis in rat hippocampal neurons following oxygen-glucose deprivation/reperfusion. Mol Med Rep 8: 1453-1459, 2013.

6. Li D, Shao Z, Vanden Hoek TL and Brorson JR: Reperfusion accelerates acute neuronal death induced by simulated ischemia. Exp Neurol 206: 280-287, 2007.

7. Di Y, Lei Y, Yu F, Changfeng F, Song W and Xuming M: MicroRNAs expression and function in cerebral ischemia reperfusion injury. J Mol Neurosci 53: 242-250, 2014.

8. Hu Y, Deng H, Xu S and Zhang J: MicroRNAs regulate mitochondrial function in cerebral ischemia-reperfusion injury. Int J Mol Sci 16: 24895-24917, 2015.

9. Min XL, Wang TY, Cao Y, Liu J, Li JT and Wang TH: MicroRNAs: A novel promising therapeutic target for cerebral ischemia/reperfusion injury. Neural Regen Res 10: 1799-1808, 2015.

10. Fasanaro P, Greco S, Ivan M, Capogrossi MC and Martelli F: MicroRNA: Emerging therapeutic targets in acute ischemic diseases. Pharmacol Therape 125: 92-104, 2010.

11. Sun Y, Gui H, Li Q, Luo ZM, Zheng MJ, Duan JL and Liu X: MicroRNA-124 protects neurons against apoptosis in cerebral ischemic stroke. CNS Neurosci Ther 19: 813-819, 2013.

12. Liu X, Li F, Zhao S, Luo Y, Kang J, Zhao H, Yan F, Li S and Ji X: MicroRNA-124-mediated regulation of inhibitory member of apoptosis-stimulating protein of p53 family in experimental stroke. Stroke 44: 1973-1980, 2013.

13. Doeppner TR, Doehring M, Bretschneider E, Zechariah A, Kaltwasser B, Müller B, Koch JC, Bähr M, Hermann DM and Michel U: MicroRNA-124 protects against focal cerebral ischemia via mechanisms involving Usp14-dependent REST degradation. Acta Neuropathol 126: 251-265, 2013.

14. Sun Y, Luo ZM, Guo XM, Su DF and Liu X: An updated role of microRNA-124 in central nervous system disorders: A review. Front Cellular Neurosci 9: 193, 2015.

15. Taniguchi K, Sugito N, Kumazaki M, Shinohara H, Yamada N, Nakagawa Y, Ito Y, Otsuki Y, Uno B, Uchiyama K, et al: MicroRNA-124 inhibits cancer cell growth through PTB1/PKM1/PKM2 feedback cascade in colorectal cancer. Cancer Lett 363: 17-27, 2015.

16. Sun Y, Ai X, Shen S and Lu S: NF- $\mathrm{BB}$-mediated miR-124 suppresses metastasis of non-small-cell lung cancer by targeting MYO10. Oncotarget 6: 8244-8254, 2015.

17. Xi ZW, Xin SY, Zhou LQ, Yuan HX, Wang Q and Chen KX: Downregulation of rho-associated protein kinase 1 by miR-124 in colorectal cancer. World J Gastroenterol 21: 5454-5464, 2015.
18. Li X, Yi S, Deng Y, Cheng J, Wu X, Liu W, Tai Y, Chen G, Zhang Q and Yang Y: MiR-124 protects human hepatic L02 cells from $\mathrm{H}_{2} \mathrm{O}_{2}$-induced apoptosis by targeting $\mathrm{Rab} 38$ gene. Biochem Biophys Res Commun 450: 148-153, 2014.

19. Kwiatkowski K, Piotrowska A, Rojewska E, Makuch W and Mika J: The RS504393 influences the level of nociceptive factors and enhances opioid analgesic potency in neuropathic rats. J Neuroimmune Pharmacol 12: 402-419, 2017.

20. Longa EZ, Weinstein PR, Carlson S and Cummins R: Reversible middle cerebral artery occlusion without craniectomy in rats. Stroke 20: 84-91, 1989.

21. Bederson JB, Pitts LH, Tsuji M, Nishimura MC, Davis RL and Bartkowski H: Rat middle cerebral artery occlusion: Evaluation of the model and development of a neurologic examination. Stroke 17: 472-476, 1986.

22. Jia D, Han B, Yang S and Zhao J: Anemonin alleviates nerve injury after cerebral ischemia and reperfusion (I/R) in rats by improving antioxidant activities and inhibiting apoptosis pathway. J Mol Neurosci 53: 271-279, 2014.

23. Livak KJ and Schmittgen TD: Analysis of relative gene expression data using real-time quantitative PCR and the $2^{-\Delta \Delta \mathrm{CT}}$ method. Methods 25: 402-408, 2001.

24. Riedl SJ and Shi Y: Molecular mechanisms of caspase regulation during apoptosis. Nat Rev Mol Cell Biol 5: 897-907, 2004

25. Zhu JR, Tao YF, Lou S and Wu ZM: Protective effects of ginsenoside $\mathrm{Rb} 3$ on oxygen and glucose deprivation-induced ischemic injury in PC12 cells. Acta Pharmacol Sin 31: 273-280, 2010.

26. Murphy KM, Ranganathan V, Farnsworth ML, Kavallaris M and Lock RB: Bcl-2 inhibits Bax translocation from cytosol to mitochondria during drug-induced apoptosis of human tumor cells. Cell Death Differ 7: 102-111, 2000.

27. Youle RJ and Strasser A: The BCL-2 protein family: Opposing activities that mediate cell death. Nat Rev Mol Cell Biol 9: 47-59, 2008.

28. Zhou H, Zhang Z, Wei H, Wang F, Guo F, Gao Z, Marsicano G, Wang $Q$ and Xiong L: Activation of STAT3 is involved in neuroprotection by electroacupuncture pretreatment via cannabinoid CB1 receptors in rats. Brain Res 1529: 154-164, 2013.

29. Lin Y, Cai B, Xue XH,Fang L, Wu ZY and Wang N: TAT-mediated delivery of neuroglobin attenuates apoptosis induced by oxygenglucose deprivation via the Jak2/Stat3 pathway in vitro. Neurol Res 37: 531-538, 2015.

30. $\mathrm{Li} \mathrm{L}, \mathrm{Li} \mathrm{H}$ and $\mathrm{Li} \mathrm{M}$ : Curcumin protects against cerebral ischemia-reperfusion injury by activating JAK2/STAT3 signaling pathway in rats. Int J Clin Exp Med 8: 14985-14991, 2015.

31. Shyu WC, Lin SZ, Chiang MF, Chen DC, Su CY, Wang HJ, Liu RS, Tsai CH and Li H: Secretoneurin promotes neuroprotection and neuronal plasticity via the Jak2/Stat 3 pathway in murine models of stroke. J Clin Invest 118: 133-148, 2008. 